\title{
INTERNAL FIXATION FOR OCCIPITO-CERVICAL FUSION
}

\author{
A. W. B. HEYWOOD, I. D. LEARMONTH, M. THOMAS
}

From the Princess Alice Orthopaedic Hospital and the University of Cape Town

\begin{abstract}
We describe a method of internal fixation for occipito-cervical fusion utilising a standard "small fragment" $T$-plate bent and fixed to the skull with three screws. The lower end of the plate is screwed and wired firmly to the spine of the axis. Of 14 patients so treated, 12 fused, one died and one failed to unite to the skull. Of eight with cord signs, seven remitted or improved and one died.
\end{abstract}

Surgical fusion of the skull to the upper cervical vertebrae may be indicated for instability, with or without neurological deficit, resulting from congenital anomaly, rheumatoid arthritis, trauma, infection or malignancy. Numerous techniques have been described. Simple onlay cancellous grafts were used by Perry and Nickel (1959) and by Newman and Sweetnam (1969), and various methods of wire fixation of grafts have been described by Cone and Turner (1937), Lipscomb (1957), Hamblen (1967) and others. Both Grantham et al. (1969) and Wertheim and Bohlman (1987) recessed and wired the grafts into the skull without penetrating the inner table. Brattström and Granholm (1976) employed wire, pins and bone cement to provide secure fixation aimed at allowing early mobilisation. Cregan (1966) seems to be the first to have used a plate screwed to the skull, and Bryan et al. (1982) employed metal plates screwed to the skull and wired to the cervical vertebrae with cement reinforcement. Ransford et al. (1986) recommended a moulded Luque rod wired to the spine and through burr holes to the skull. An anterior retropharyngeal approach was described by de Andrade and Macnab in 1969.

Our concern at the deaths, infections and variable fusion rates reported for other methods, and three of our own failures after onlay'grafts, led us to develop a simple method of screw, plate and wire fixation. We describe the technique and results in 14 cases.

Skull thickness. To assess the safety of screwing a surgical

A. W. B. Heywood, MCh (Orth), FRCS Ed, Professor of Orthopaedic Surgery

I. D. Learmonth, FRCS Ed, FCS(Orth) SA, Orthopaedic Consultant The Princess Alice Orthopaedic Hospital, University of Cape Town, Private Bag, Plumstead 7800, Republic of South Africa.

M. Thomas, FRCS Ed, Orthopaedic Registrar

Charing Cross Hospital, Fulham Palace Road, London W6 8RF, England.

Correspondence should be sent to Professor A. W. B. Heywood at the Department of Orthopaedic Surgery, University of Cape Town, Observatory 7925, Republic of South Africa.

(C) 1988 British Editorial Society of Bone and Joint Surgery

$0301-620 \mathrm{X} / 88 / 5181 \$ 2.00$

J Bone Joint Surg [Br] 1988:70-B:708-11. plate to the basi-occiput we used a caliper to measure the thickness of the relevant area in 20 cadaver skulls. The results, charted in Figure 1, show the skull to be less than $9 \mathrm{~mm}$ thick around the foramen magnum, and especially thin laterally in the cerebellar fossa. The maximum thickness (11 to $17 \mathrm{~mm}$ ) is encountered under the external occipital protuberance; from this area a midline ridge extends caudally, becoming narrower but retaining a minimum thickness of $9 \mathrm{~mm}$ as far as $20 \mathrm{~mm}$ from the foramen magnum. The main venous sinuses lie under thick bone just caudal to the external occipital protuberance.

\section{PATIENTS AND METHODS}

Table I summarises the 14 patients who underwent occipitocervical fusion in our unit between 1979 and 1986. The preponderance of eight rheumatoid patients reflects our particular interest in that condition and not the expected overall incidence. Five of the 14 patients underwent our technique after failure of other methods. Peri-operative management. Four patients still ambulant with long tract signs wore a SOMI brace prior to surgery; three paraplegics were managed with halo traction. All but one remitted or improved on this regime before they came to operation. The paraplegic who failed to improve on halo traction also required tracheostomy before surgery.

Eight patients had halo-body orthoses fitted before operation, and we now recommend this as the safest form of postoperative support. Rigid immobilisation and the high incidence of cord signs necessitated the use of a fibre-optic laryngoscope for intubation at induction of anaesthesia. After operation, extubation was delayed until the patient was awake and "fighting the tube". External support was continued until 12 weeks after operation.

Operative technique. Through a vertical mid-line incision, the field is exposed from the external occipital protuberance to the cervical level required, usually the spine of the axis. The spine and laminae of the axis, the 


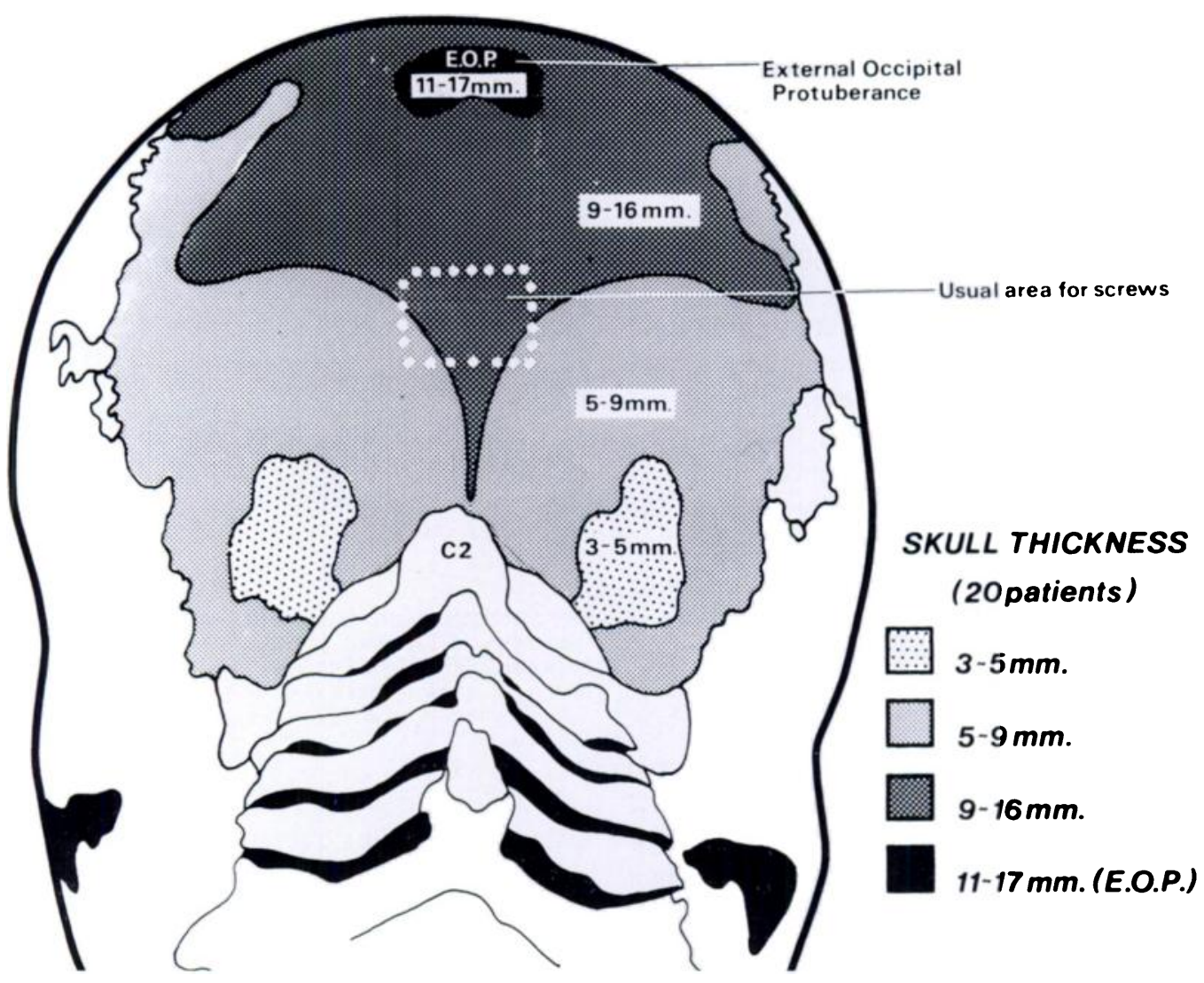

Fig. 1

Thickness of the skull in the basi-occiput. Maximum and minimum thicknesses were measured with calipers in 20 cadaver skulls. Based on these measurements, we have reduced the maximum safe length of screw to $8 \mathrm{~mm}$.

Table I. Summary of patients, fusion rate and neurological state

\begin{tabular}{|c|c|c|c|c|c|c|}
\hline & $\begin{array}{l}\text { Rheumatoid } \\
\text { arthritis }\end{array}$ & $\begin{array}{l}\text { Ankylosing } \\
\text { spondylitis }\end{array}$ & $\begin{array}{l}\text { Congenital } \\
\text { anomaly }\end{array}$ & $\begin{array}{l}\text { Old } \\
\text { trauma }\end{array}$ & $\begin{array}{l}\text { Idiopathic } \\
\text { atlanto-axial } \\
\text { dislocation }\end{array}$ & Total \\
\hline Number of patients & 8 & 2 & 2 & 1 & 1 & 14 \\
\hline Successful fusion & 7 & 2 & 2 & 1 & died & 12 \\
\hline Cord compromise & 4 & 0 & 2 & 1 & 1 & 8 \\
\hline Remission* of cord signs & 4 & 0 & 2 & 1 & 0 & 7 \\
\hline
\end{tabular}

- By remission we mean an improvement of 1 or 2 grades (see text)

posterior arch of the atlas and the adjacent skull are rawed with a burr (elevators and gouges are avoided because of the mobility of the bony components and danger to the underlying cord). A standard $39 \mathrm{~mm}$ small fragment $T$-plate is bent backwards at its head/shaft junction so that the head of the plate fits the skull with the shaft downwards across the tip of the spine of the axis. The bend is made just proximal to the topmost shaft screw hole, not through it. The tip of the shaft bearing the terminal screw is now bent $45^{\circ}$ forwards immediately below the spine of the axis (see plate contours in Figures 2 and 4). A $2 \mathrm{~mm}$ drill bit is used with a sleeve to limit depth to $10 \mathrm{~mm}$. The surgeon's hands rest on the patient's back to control drill penetration. After penetrating the outer table of the skull, first a probe and then the drill is pushed gently deeper to feel the inner table. Drilling of the inner table is done with a gentle but firm bouncing action, stopping when one feels the hardening of resistance which immediately precedes the final penetration. There is no space between dura and cerebellum and we now heed Bryan et al. (1982) who advise that the screws should not penetrate the inner table. A $2.7 \mathrm{~mm}$ screw is selected, 8 or $10 \mathrm{~mm}$ in length, its threads are counted and just that number of turns is 
employed to tap the hole. The screw is driven in, and the same technique applied to the other two screws in the head of the plate.

Fixation of the lowest hole of the plate is best achieved by a screw placed obliquely upwards and forwards through the spine of the axis as shown in Figures 2 and 4 . The middle (oval) hole of the plate is wired to a hole made with a heavy towel clip, also through the spine of the axis. The wire and the bottom screw are at right angles to each other, giving secure fixation. Cases requiring downward extension of the fusion may require a longer plate, with wiring to the relevant lower vertebrae. We have never found it necessary to use wire round the posterior arch of the atlas: in all cases, the fixation felt rigid without this. Cancellous strip grafts are placed on the rawed bone surfaces which are easily accessible under the plate.

\section{RESULTS AND COMPLICATIONS}

As summarised in Table I, 12 of the 14 patients fused solidly with relief of pain. In three, all managed in SOMI braces, there was partial extrusion of the lower screw or screws, without affecting bone union. One had inadvertent screw penetration of a congenitally thin skull without any neurological consequence (Fig. 5). There was one probable failure of fusion (Fig. 4) and one postoperative death.

The probable failure occurred in a rheumatoid arthritic who had already had two failures of atlantoaxial fusion for instability at that level (Fig. 3). She fell in her halo-body jacket three weeks after operation, and radiographs one year later show a pseudarthrosis at the skull but with probable early atlanto-axial fusion (Fig. 4). Pain was reduced but not abolished.

The death occurred in a patient with paraplegia caused by unexplained irreducible atlanto-axial

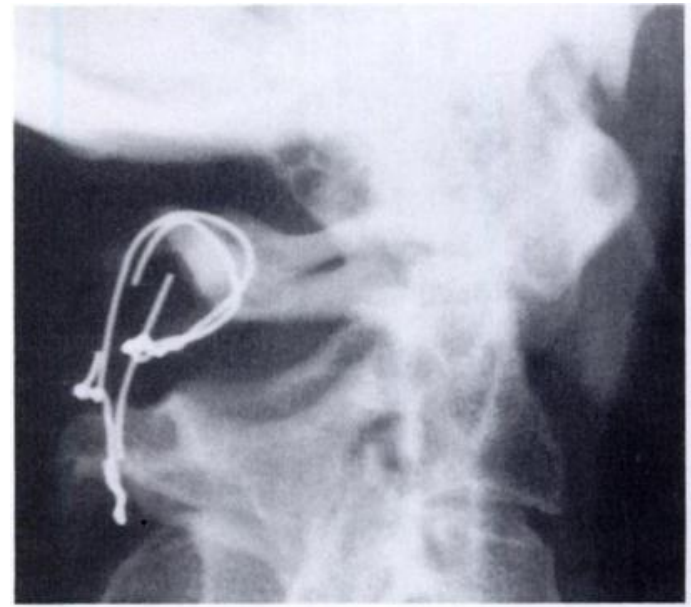

Fig. 3

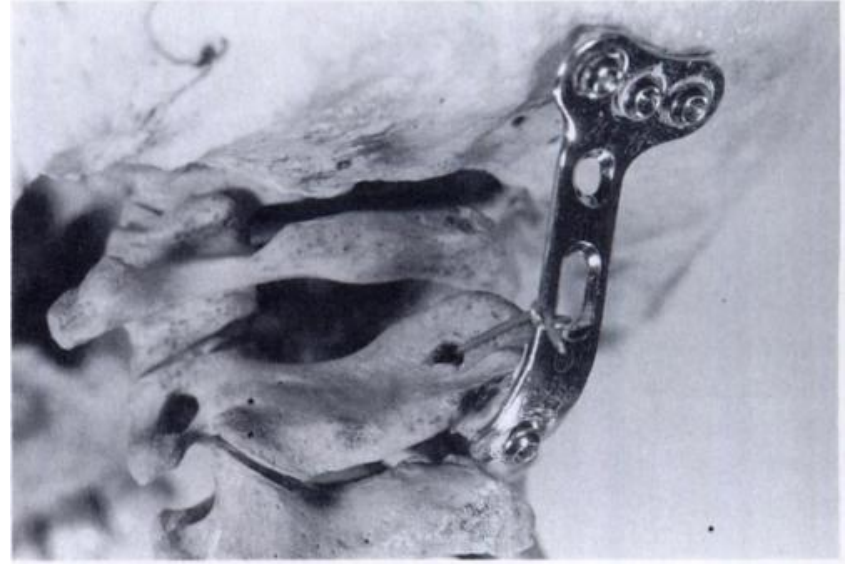

Fig. 2

Dry specimen with plate, wire and screws in place. To fit the inclination of the skull, the head-neck junction of the plate is bent backwards 20 to $30^{\circ}$. The bottom hole is bent about $40^{\circ}$ forwards to enable its screw to track obliquely upwards through the spine of the axis. The middle (oval) hole is wired to a hole made though the spine of the axis.

dislocation. Halo traction for four weeks failed to improve cord function and he needed tracheostomy. He was referred by a neurosurgeon who removed the odontoid process through the pharynx as recommended by Crockard et al. (1986) before we performed a posterior occipitocervical fusion. Marginal neurological improvement occurred after two weeks, the tracheostomy tube was removed at four weeks, and the patient was encouraged to start sitting out of bed in his halo-body jacket; but death from respiratory arrest occurred suddenly six weeks after operation. Autopsy showed persistent compression of the medulla and cord in spite of complete removal of the dens. Progressing union of the graft was demonstrated.

Cord signs were graded thus: $0=$ normal; $1=$

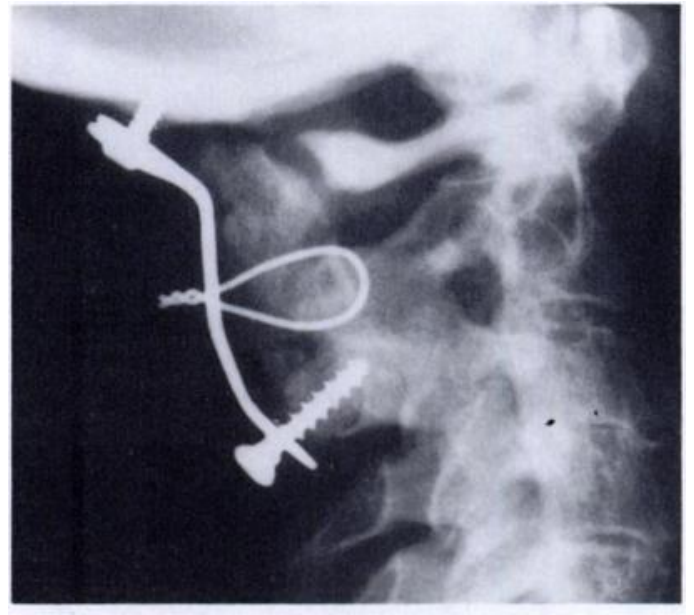

Fig. 4

Figure 3 - Broken wires and graft resorption after a Gallie atlanto-axial fusion for rheumatoid arthritis. Figure 4 Nine months after attempted occipito-cervical fusion, there is apparent partial pull-out of skull screws with pseudarthrosis, following a fall. This was the only case in which a screw was inserted into C3; normally, when fixation extends below $\mathrm{C} 2$, a wire is used. 


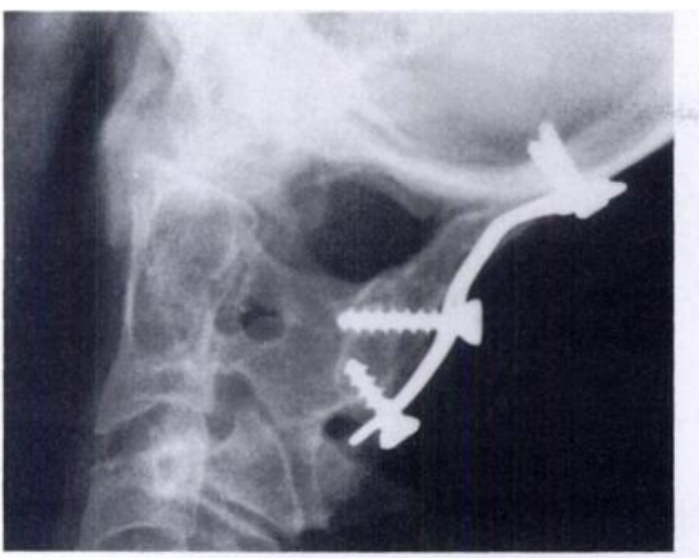

Fig. 5

Inadvertent screw penetration of a congenitally thin basi-occiput during fusion for congenital spine anomaly. The graft has united and the patient has lost her preoperative cord signs and pain. Although no complications were caused by the screws, we advise against penetration of the inner table.

paraesthesia, extensor plantar reflexes or hyper-reflexia; $2=$ muscle weakness; and $3=$ paraparesis. Neurological improvement of one or two grades occurred in seven out of eight patients with cord involvement, the exception being the fatality referred to above. Two rheumatoid paraparetics returned to walking, though one of them still had spasticity. Two rheumatoid patients, two with congenital anomalies and one with an old traumatic atlanto-axial dislocation lost their weakness, spasticity and/or paraesthesia.

\section{DISCUSSION}

As regards the safety of screwing the plate to the skull, we encountered no complications from inadvertent penetration of the inner table in one case (Fig. 5). Nevertheless, we now avoid penetration of the inner table (Bryan et al. 1982).

We use a $\mathrm{T}$-plate rather than a straight one with mid-line screws for two reasons. In the first instance, mechanical fixation is better: rotation is firmly resisted, and each of the three screws resists vertical pull-out whereas in a straight plate only the lowest screw would do so. In the second instance, any further screws running cranially are likely to reach the confluence of sinuses at the internal occipital protuberance so that thrombosis might be caused by inadvertent screw penetration. With one exception (Fig. 4) skull fixation has always remained totally rigid. Fixation to the spine of the axis was sometimes doubtful in the earlier cases when two screws were used at this site (Fig. 5). The best fixation is usually by a lower screw and an upper wire; the screw holds the plate against vertical and coronal movement while the wire resists anteroposterior stress. We prefer to avoid cement, except for malignancy, because of its irritative effects on bone (Freeman, Bradley and Revell 1982).
Surgical decompression for myelopathy in the unstable upper cervical spine has been discouraged by the experience of Meijers et al. (1974) and Conaty and Mongan (1981); it did not help the one patient on whom we tried it. It appears to be unnecessary when cord compression remits with traction or immobilisation. If necessary, anterior decompression may be done later. Our single postoperative death occurred in what seems to us to be the insoluble case: failure to remit on preoperative traction, followed by only marginal improvement after fusion and complete removal of the compressing odontoid process. In keeping with other published series, our best results followed early intervention.

We wish to thank Dr Jean Marus, neurosurgeon of Groote Schuur Hospital, for permission to include his patient in this series.

No benefits in any form have been received or will be received from a commercial party related directly or indirectly to the subject of this article.

\section{REFERENCES}

Brattström H, Granholm L. Atlanto-axial fusion in rheumatoid arthritis: a new method of fixation with wire and bone cement. Acta Orthop Scand 1976;47:619-28.

Bryan WJ, Inglis AE, Sculco TP, Ranawat CS. Methylmethacrylate stabilization for enhancement of posterior cervical arthrodesis in rheumatoid arthritis. J Bone Joint Surg [Am] 1982;64-A :1045-50.

Conaty JP, Mongan ES. Cervical fusion in rheumatoid arthritis. $J$ Bone Joint Surg [Am] $1981 ; 63-A: 1218-27$.

Cone W, Turner WG. The treatment of fracture-dislocations of the cervical vertebrae by skeletal traction and fusion. J Bone Joint Surg 1937:19:584-602.

Cregan JC. Internal fixation of the unstable rheumatoid cervical spine. Ann Rheum Dis 1966:25:242-52.

Crockard HA, Pozo JL, Ransford AO, Stevens JM, Kendall BE, Essigman WK. Transoral decompression and posterior fusion for rheumatoid atlanto-axial subluxation. J Bone Joint Surg [Br] 1986:68-B:350-6.

de Andrade JR, Macnab I. Anterior occipito-cervical fusion using an extra-pharyngeal exposure. J Bome Joint Surg [Am] 1969:51-A:1621-6.

Freeman MAR, Bradley GW, Revell PA. Observations upon the interface between bone and polymethylmethacrylate cement. $J$ Bone Joint Surg [Am] 1982;64-A :489-93.

Grantham SA, Dick HM, Thompson RC Jr, Stinchfield FE. Occipitocervical arthrodesis: indications, technic and results. Clin Orthop 1969;65:118-29.

Hamblen DL. Occipito-cervical fusion: indications, technique and results. J Bone Joint Surg [Br] 1967;49-B:33-45.

Lipscomb PR. Cervico-occipital fusion for congenital and posttraumatic anomalies of the atlas and axis. $J$ Bone Joint Surg [Am] 1957;39A :1289-301.

Meijers KAE, van Beusekom GTh, Luyendijk W, Duijfjes F. Dislocation of the cervical spine with cord compression in rheumatoid arthritis. J Bone Joint Surg [Br] 1974;56-B:668-80.

Newman P, Sweetnam R. Occipito-cervical fusion: an operative technique and its indications. $J$ Bone Joint Surg $[\mathrm{Br}]$ 1969;51-B:423-31.

Perry J, Nickel VL. Total cervical-spine fusion for neck paralysis. $J$ Bone Joint Surg [Am] 1959;41-A:37-60.

Ransford AO, Crockard HA, Pozo JL, Thomas NP, Nelson IW. Craniocervical instability treated by contoured loop fixation. $J$ Bone Joint Surg [Br] 1986;68-B:173-7.

Wertheim SB, Bohlman HH. Occipitocervical fusion: indications, technique, and long-term results in thirteen patients. $J$ Bone Joint Surg [Am] 1987;69-A :833-6. 